philosophy and sociology of science, the mechanics of sediment transport, radiocarbon dating, the evolution of behaviour, the theory of numbers, mathematical statistics and probability, problems of nuclear structure, molecular quantum mechanics and high-energy nuclear physics; the twentieth Cold Spring Harbor Symposium on Quantitative Biology, at which special emphasis was given on population genetics; and the fourteenth Growth Symposium of the Society for the Study of Development and Growth. Some 137 scientists from the United States and abroad were assisted to attend the Garden Research Conferences.

Appropriations for services and equipment for the International Geophysical Year totalled 1,914,957 dollars, and during the next fiscal year the Foundation plans to make a full evaluation of current basic research activities on synthetic rubber, the average annual expenditure on contract research, which at universities and other institutions during the quinquennium ending June 30,1955 , exceeded $1,118,000$ dollars and at the government laboratory at Akron 1,094,000 dollars. The Foundation assumed responsibility on July 1, 1955, for administering the Federal programme for basic research on synthetic rubber. At the request of the Bureau of the Budget the Foundation has also given special attention to the indirect costs of research supported by Federal grant or contract at educational institutions and has recommended procedure for reimbursing such indirect costs where requested. Adoption of the policy is estimated to involve an additional cost to the Foderal Government of not more than 8 million dollars, or $2 \cdot 3$ per cent of the present Federal expenditure on research in such institutions. As regards the loyalty and security considerations in making grants for non-classified scientific research, Dr. Waterman affirms that the Foundation will not knowingly support anyone who is, by admission or conviction, disloyal to the United States; its grants will be made on the judgment of outstanding scientists in his field and of persons possessing personal knowledge of his corapetence and integrity.

\section{RESEARCH IN SEMICONDUCTORS SYMPOSIUM AT OTTAWA}

A SYMPOSIUM on semiconductors took place during February 13-14 at the National Research Council Laboratories, Ottawa, at the invitation of the Low Temperature and Solid State Physics Group of the Division of Pure Physics ; the arrangements followed the lines of the symposium on melting reported in Nature of January 7 . The chairmen were Dr. D. K. C. MacDonald and Dr. W. B. Lewis.

When opening the meeting, Dr. MacDonald said that the subject of semiconductors was chosen because of widespread interest throughout Canadian universities and laboratories. The Low Temperature and Solid State Physics Group is specifically interested in bulk properties, and is investigating magnetic susceptibility and the thermal and electrical conductivities, as well as the occurrence of semiconductivity in intermetallic compounds; but the scope of the meeting in general would be much wider. Later, Dr. Lewis said that quite apart from the revolution it has effected in electronics, research in semiconductors may well provide a basis for a new statistical treatment of processes whereby energy is stored and dispersed. In nuclear reactors, energy is produced initially in a very intense form, and dispersed under conditions far from thermal equilibrium. The processes of dispersal and degradation of this energy, until it emerges as heat, seem to require a statistical approsch which would be essentially different from the traditional equilibrium theories of thermodynamics and thermal fluctuations, and yet would to some extent take their place.

In the first of two papers, R. E. Burgess (University of British Columbia) outlined the theory of statistical fluctuations of both the spatial and temporal distributions of electrons among the energy-bands and -levels in a semiconductor ; these give rise to 'patch' effects and noise, respectively, and the theory can be compared with experiment. In his second paper, mathematical analysis of the characteristics of germanium point-contact diodes (showing voltage turnover) was shown to lead to severe restrictions on conjectural models : possible mechanisms were discussed, and in particular a model due originally to Gunn appeared to be consistent with these restrictions.

W. B. Pearson (National Research Council, Ottawa) described briefly the concept of the semiconducting valence bond, which has proved fruitful both in accounting for known semiconductors and in predicting new ones, and went on to discuss further aspects of bonding in semiconductors. G. F. Bolling and J. W. Rutter (University of Toronto) showed how both the grain structure and the distribution of impurities in solid germanium are affected by the way in which it is formed from the melt. This is important both for obtaining distributions required for electronic devices and for knowing how to avoid the formation of undesirable substructures in the solid. J. Sharma (National Research Council, Ottawa) described an experimental frequency analysis of the glow peaks obtained at different temperatures from luminescent alkali halides. The luminescence is caused by colour centres, and a provisional model was put forward to account for the spectra caused by different types of centre. Two chemists, D. M. J. Compton and T. C. Waddington (National Research Council, Ottawa), described experiments on the organic semiconductor anthracene, with various kinds of electrode, various impurities and under various conditions of illumination. Among properties measured have been the electrical conductivity, Hall effect and distribution of space-charge. Marked differences in behaviour from typical inorganic semiconductors require correspondingly different explanations.

Other papers were given by J. H. Simpson (National Research Council, Ottawa) on the calculation of the ground-state of an $F^{\prime}$-centre; by $J$. Rolfe (National Research Council, Ottawa) on the design of high-frequency transistors ; by Z. Szepesi (Canadian Marconi Co.) on the similarity in electrical characteristics between condensed layers and single crystals of cadmium sulphide; by F. T. Hedgcock (National Research Council, Ottawa) on the magnetic properties of very dilute germanium alloys down to $8^{\circ} \mathrm{K}$. ; by R. P. Singh (National Research Council, Ottawa) on the functions developed by Wannier for use in the theory of a perturbed lattice; and by A. O. Barut (University of Montreal) on the conditions needed for a rigorous quantum statistical derivation of thermodynamics.

An informal report of the proceedings is being prepared, similar to that produced for the previous symposium on melting and diffusion.

T. H. K. BARRON 